\title{
Free recall of intra-list items as a function of serial position and association value
}

IAN REID, DENNIS ROBERTS AND F. J. KING

INSTITUTE OF HUMAN LEARNING, FLORIDA STATE UNIVERSITY

The present study was undertaken to extend the findings of a previous investigation by King, Reid, \& Roberts (1966). Eight lists of nonsense syllables were developed, each list containing four low and fourhigh-association value syllables. In four lists, a L, H, L, H alternation scheme was used, while the opposite arrangement was utilized in the other four lists. The two alternation patterns produced different serial position curves. This finding was essentially in agreement with the earlier study.

Recently, King, Reid, \& Roberts (1966) showed that free recall of items within lists of words depended on their serial position and association value (dominance level). Eight 8-item lists of meaningful words were given for recall. Each list contained four low- and four high-association value (dominance level) items, alternated on either a high, low high, low, etc. or low, high, low, high etc. basis. Each of the above alternation patterns produced opposite up-down effects in the serial position curves. The present study was intended to investigate whether or not the same effect would be found when using lists of nonsense syllables.

Method

Materials. Eight 8-item lists of nonsense syllables were constructed from Glaze's (1928) material. An equal number of high (100\%) and low (0-7\%) association value syllables were chosen. Four high- and four lowassociation value syllables were randomly assigned to each of the eight lists. In four of the lists, syllables were alternated on a high, low, high, low basis, while the pattern for the remaining lists was just the reverse. The odd numbered lists were arranged on the high, low, high, low alternation pattern, while the even numbered lists followed the low, high, low, high alternation scheme.

These materials were printed on transparencies and shown by slide projector. Each $\mathrm{S}$ was given a mimeographed sheet of paper on which to write the recall words. All timing was done with a stop watch.

Procedure. Each word was individually flashed on the projection screen. The exposure interval was operated manually and was maintained between 1.5 and $2.0 \mathrm{sec}$. After a complete list was presented, a blank slide would appear. This was the $S^{\text {'s }}$ cue for recall. Fortyfive sec. were given as a recall interval. After the first list was finished, the remaining seven lists were presented in the same fashion. A short pause occurred between the presentation of the fourth and fifth lists due to a change in the slide projector cartridges. All Ss received the same order of list presentation. All papers were collected at the end of the eighth list.
Subjects. Fifty-four Ss were taken from undergraduate Educational Psychology classes at Florida State University. Both male and female Ss were included in the sample.

\section{Results and Discussion}

Analysis of variance was carried out with Ss, lists, and positions as variables. The main effects of $\mathbf{S s}_{\text {, }}$ position, lists, and the list by position interaction were all significant at the .01 level. All other interactions were found to be nonsignificant. These findings are essentially in agreement with those reported in King, Reid, \& Roberts (1966), except for the significant list effect. Since all Ss received the same lists of nonsense syllables in the same order, lists and order were confounded. Therefore, the significant list effect can probably be attributed to proactive inhibition. In fact, mean recall dropped from the first to the last list (4.64 to 2.16) except for a small increase between the fourth and fifth list. This can probably be accounted for by the rest interval between the presentation of these lists.

Figure 1 presents a comparison of the serial position curves for the lists where the low, high, low, high and high, low, high, low association value schemes were used. Also plotted is the average curve when the different alternation patterns are summed together. Notice that a very pronounced up-down effect was obtained. The fact that the difference between the recall of highand low-association value nonsense syllables at any given position was consistently large seems to be of general importance, since in the previous study the difference in recallability of high and low dominance level items at any given serial position tended to be smaller. This indicates that the difference in degree of

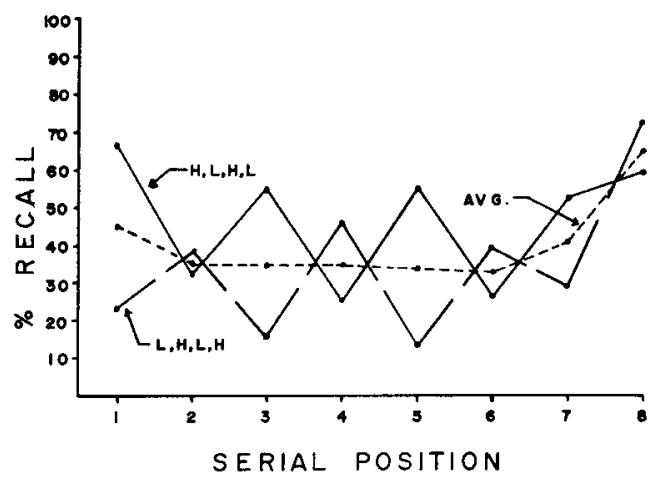

Fig. 1. Serial position curves for lists where association value was varied from position to position. 
meaningfulness between high and low association value nonsense syllables is greater than the corresponding difference between high and low dominance level words. This interpretation seems reasonable since low dominance level words are commonly known nouns whereas low association value nonsense syllables are essentially unfamiliar.

\section{References}

Glaze, J. A. The association value of nonsense syllables. $J$. genet. Psychol., 1928, 35, 255-267.

King, F. J., Reid, I., \& Roberts, D. M. Free recall of intra-list items as a function of serial position, association value and conceptualization. Psychon. Sci, 1966, 4(8), 311-312.

\section{Developmental level and concept learning: A reply to Te Vault et al}

\section{by Stanley R. Friedman}

Te Vault et al (1966) have described an experiment which they feel calls into question certain results obtained by previous investigators (Klugh et al, 1964, 1965; Friedman, 1965; Pishkin \& Rosenbluh, 1966) regarding interactions between developmental level and concept learning. Specifically, they question the hypothesis presented by this writer that a demonstrated inversion at the fourth-grade level may be due to the inefficient use of a newly developing mediation process. I shall analyze a number of points raised by Te Vault et al:

1. The author's note (p. 168) "However, it was the fourth grades (9-year olds) which were specifically designated by Friedman as the inverted group, and it is the comparison of fourth-grade children to thirdgraders which is crucial to the hypothesis. "I did not at any point say "9-year olds;" I did say "fourth-grade." There is a difference. (My fourth-graders, in any case, were run in both November and March, and were closer to 10- than 9-year olds.) Klugh et al (1964) also specified grade level; in their 1965 study, age was used, and specified at 9-10 years. Te Vault et al say they used 8- and 9-year old children, specifying neither mean ages nor grades. A reasonable test of the hypothesis would certainly have included a 10-year group, in any case.

2. It has not been claimed that fourth-graders are duller than third-graders, merely that they prematurely form hypotheses when a task lends itself to such a process. However, given a task presenting little opportunity for generation of relatively complex hypotheses, they (fourth-graders) would utilize a simpler associationistic type of responding. Further, they used a correction procedure which would certainly serve to inhibit the formation of complex hypotheses, since each time the $S$ is wrong, he does not have to speculate (i.e., hypothesize) as to the correct response, $E$ informs him of the correct response!

3. They have used a different response measure, i.e., total number of correct responses on the 10 trials. This measure is not necessarily comparable to one using percentage successful Ss at each grade level. Further, it is unclear how they get an error term having 780 df from a 20 cell matrix with a single score per cell (a similar problem with df arises with their post hoc analysis).
4. The fact that no inversion of ranks appeared in the 9-year old group data of the "deviant experimenter" would seem to indicate, if anything, that it was not the experimenter but one or both of the 8-year groups tested by this $\mathrm{E}$ which was deviant. At any rate, why should such an inversion of ranks indicate that anyone was deviant; the fact that in one case an $E$ gets four bright Ss does not guarantee his continuing to be so fortunate in other situations.

5. The fact that the elimination of data of one $E$ produced nonsignificance in all main effects and interactions (other than $\mathrm{E}$ main effect) appears to indicate that the "mediating condition" did not readily lend itself to mediating behavior (what the $\mathrm{E}$ calls the condition and what the $S$ takes it to be do not necessarily coincide) since these Ss did not solve the problem more efficiently than the Ss in the nonmediating condition. This fact alone casts considerable doubt on the validity of their study.

6. Eight experimenters were used in my study (as can be seen in the footnote); all but one of the experimenters participated in the testing of all grade levels; the inversion was found with each experimenter's portion of the total N. Another point is that in my study, each $\mathrm{S}$ continually faced and "interacted" with a wooden display panel, contrasted with the E-S interaction (nonstatistical) inherent in the methodology used by Te Vault et al.

7. And last but certainly not least, the earlier results (Friedman, 1965) have since been replicated (the manuscript presently being completed).

\section{References}

Friedman, S. R. Developmental level and concept learning: Confirmation of an inverse relationship. Psychon. Scr., 1965, 2, 3-4

KIugh, H. E., Colgan, K., \& Ryba, J. A. Developmental level and speed of relational concept formation: A possible inverse rela-tionship. Psychon. Sci., 1964, 1, 89-90

Klugh, H. E., \& Roehl, K. Developmental level and concept learning: Interaction of age and complexity. Psychon. Sci., 1965, 2, 385-386

Pishkin, V., \& Rosenbluh, E. S. Concept identification of auditory dimensions as a function of age and sex. Psychon. Sci., 1966. 4. $165-166$.

Te Vault, R. K., Bailey, Melinda, Cagan, Elizabeth, Dionis, Joan, \& Figelman, Edith. Developmental level and concept learning: A possible artifact. Psychon. Sci., 1966, 5, 167-168. 